\title{
The 245 kb Amplified Chromosome of Leishmania (V.) braziliensis Contains a Biopterin Transporter Gene
}

\author{
MCR Sampaio/ ${ }^{+}$, YM Traub-Cseko*
}

\begin{abstract}
Departamento de Biologia Celular e Genética, Universidade do Estado do Rio de Janeiro, Rua São Francisco Xavier 524, 20550-013 Rio de Janeiro, RJ, Brasil *Departamento de Bioquímica e Biologia Molecular, Instituto Oswaldo Cruz-Fiocruz, Rio de Janeiro, RJ, Brasil

Leishmania (V.) braziliensis M2903 presents a small linear and stable $245 \mathrm{~kb}$ chromosome originating from a genomic amplification. Similar amplifications present in other species of Leishmania contain a gene coding for a biopterin transporter. Since Leishmania is auxotrophic for this metabolite, this amplification could result from the need to better capture biotpterin from growth media under specific circumstances. In this paper we show that this gene is also present in L. (V.) braziliensis small chromosome, which shares sequences with other genomic amplifications already described.
\end{abstract}

Key words: Leishmania (V.) braziliensis - small chromosome - genomic amplification

Leishmania (V.) braziliensis is responsible for mucocutaneous leishmaniasis, present in the New World. Leishmania genome does not compact during the cell cycle, so a karyotype can only be obtained through pulsed field gel electrophoresis (PFGE). Leishmania karyotypes show polymorphism among species and strains (Lighthall \& Giannini 1992). The appearance of genomic amplifications is common, in the form of linear or circular small chromosomes. These amplifications can appear spontaneously, or as a result of drug pressure, being stable or not after appearance (Beverley 1991). Spontaneous amplifications are seen in many Leishmania species, the best studied ones being from the LD1 amplicon type (Segovia \& Ortiz 1997). The $245 \mathrm{~kb}$ small chromosome of $L$. (V.) braziliensis M2903 falls into this group (Scholler et al. 1986, Fu et al. 1998, Stiles et al. 1999). The functions for these amplifications are still not clear. The finding of a gene coding for a biopterin transporter (BT1) in small amplified chromosomes, and since Leishmania are auxotrophic for this metabolite, indicates that biopterin uptake could be the underlying reason for the appearance of these amplifications (Moore \& Beverley 1996). In the present work we show the presence of BT1 in the small chromosome of $L$. $(V$.) braziliensis, and that it shares sequences with similar genomic amplifications present in Leishmania (L.) donovani and Leishmania (L.) major.

L. (V.) braziliensis strain M2903 (MHOM/BR/75/ M2903) isolated in Serra dos Carajás, State of Pará, was used in these studies. Two lineages from different sources were obtained: one containing the small $245 \mathrm{~kb}$ chromosome, here denominated M2903(+), was obtained from Dr

${ }^{+}$Corresponding author. Fax: +55-21-2587.7377. E-mail: csampaio@uerj.br

Received 23 July 2002

Accepted 7 March 2003
Gabriel Grimaldi (Instituto Oswaldo Cruz, Rio de Janeiro, RJ); another, not containing the small chromosome, here denominated M2903(-), was obtained from Dr Diane McMahon-Pratt (Yale University, New Haven, CT). Both were maintained as culture promastigotes in modified M199, with $10 \%$ fetal bovine serum at $24^{\circ} \mathrm{C}$ (Kapler et al. 1990). PFGE was carried out in a CHEF DRII apparatus (BioRad) (Chu et al. 1986) and electrophoresis conditions are described in the figures legends. Gels were transferred to nylon membranes and hybridized according to standard conditions (Tavares et al. 1992). We used a BT1 probe

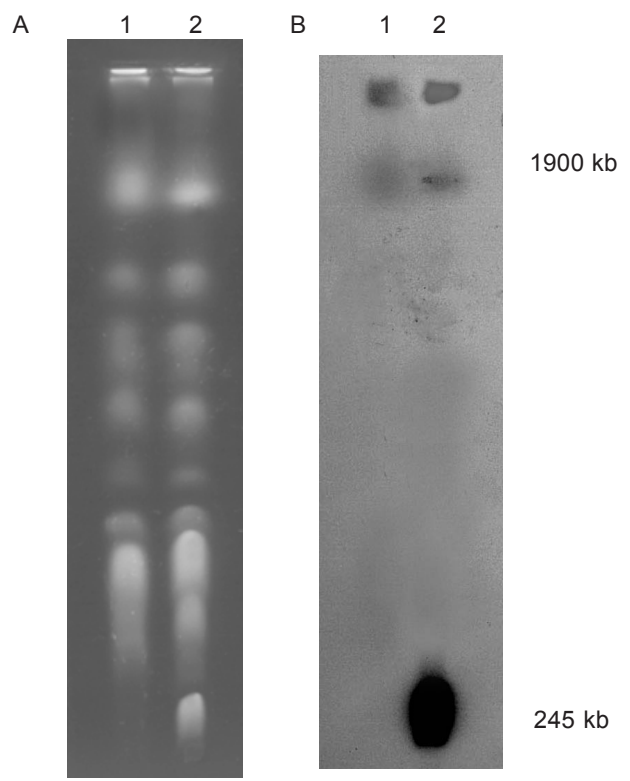

Fig. 1 - A: pulsed field gel electrophoresis; 1: Leishmania (V.) braziliensis M2903(-) and, 2: L. (V.) braziliensis M2903 (+). Electrophoresis conditions: $\mathrm{V}=175 \mathrm{~V} ; 1.5 \%$ agarose in $0.5 \times \mathrm{TBE}$ (45mM Tris; $45 \mathrm{mM}$ boric acid; $1 \mathrm{mM}$ EDTA $\mathrm{pH} 8.3$ ); $\mathrm{T}=14^{\circ} \mathrm{C}$; run length $24 \mathrm{~h}$; B: autoradiography after hybridization against the small chromosome itself. The probe was prepared according to Beverley (1990). 


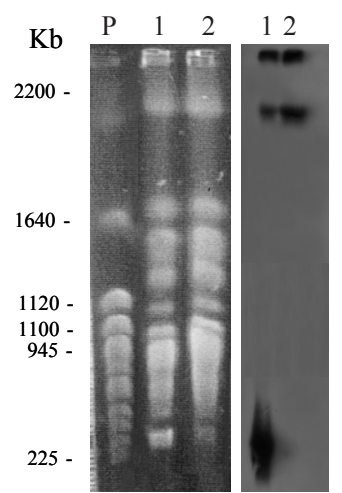

A

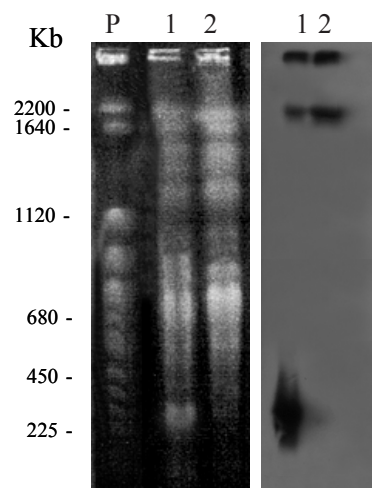

B
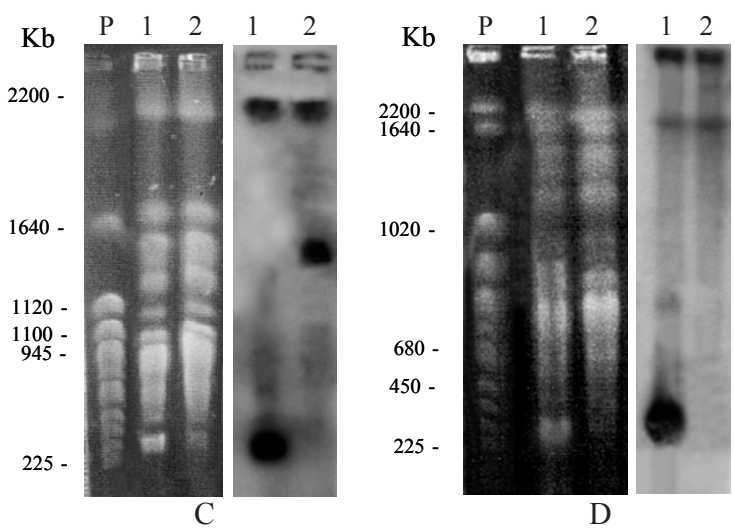

Fig. 2 - P: yeast chromosomes molecular weight markers (sizes indicated in the figure) 1: Leishmania (V.) braziliensis M2903(+) and, 2: L. (V.) braziliensis M2903 (-). In A and C, pulsed field gel electrophoresis (PFGE) in ideal conditions for resolution above $1000 \mathrm{~kb}$ chromosome sizes $\left(\mathrm{V}=175 \mathrm{~V} ; \mathrm{T}=14^{\circ} \mathrm{C}\right.$; agarose $1 \%$ in $0.5 \mathrm{x}$ TBE; pulses from 100 to $200 \mathrm{sec}$; run length: $\left.24 \mathrm{~h}\right)$. In B and D, PFGE in ideal conditions for resolution of chromosomes below $1000 \mathrm{~kb}\left(\mathrm{~V}=175 \mathrm{~V} ; \mathrm{T}=14^{\circ} \mathrm{C}\right.$; agarose $1 \%$ in $\mathrm{TBE} 0.5 \mathrm{x}$; pulses from 50 to $100 \mathrm{sec}$; run length: $24 \mathrm{~h}$ ). A and B were hybridized against BT1 probe and C and D were hybridized against p7R50-19 probe. The hybridization was done at $65^{\circ} \mathrm{C}$ and three washes at $1 \mathrm{X}$ SSC and $0.5 \%$ SDS.

[1.4 kb BamHI-BglII fragment within the BT1 gene of $L$. (L.) donovani, kind gift of Dr Jeffrey Moore] and p7R5019 probe, a random $1.9 \mathrm{~kb}$ Pst I fragment from the $L$. (L.) major 715 class small chromosome (Beverley \& Coburn 1990) against chromoblot obtained by PFGE.

The hybridization in Fig. 1, using the small chromosome itself as probe, shows the recognition of the large chromosome $(1900 \mathrm{~Kb})$ that gives rise to the $245 \mathrm{~kb}$ linear amplification, and confirms the presence of the genomic amplification in lineage M2903(+). Similar results are seen in Fig. 2 where BT1 and p7R-50-p19 probes from $L$. (L.) donovani and $L$. (L.) major small chromosomes were used, showing that these species share common genes with the L. (V.) braziliensis M2903 small chromosome.

Hybridization with BT1 (Fig. 2) confirms the presence of the biopterin transporter gene in the small $245 \mathrm{~kb}$ chromosome, and in the large source chromosome, as had been previously observed in $L$. (L.) donovani (Lemley et al. 1999). Hybridization with p7R-50p19 reveals not only the amplified small chromosome and the source chromosome, but also, in the case of M2903(-), labeling of a chromosome of approximately $1600 \mathrm{~kb}$. This might be due to the presence of repetitive sequences present in more than one chromosome, since this probe is a random fragment of a small chromosome. The presence of BT1 gene in the amplicon, and preliminary results indicating higher BT1 RNA levels in M2903(+), suggest that the amplification of this essential gene might provide a nutritional advantage to lineage M2903(+). This was corroborated by growth curves of the two strains, in the presence of the metabolite (manuscript in preparation).

Our results point to the consistent presence of the BT1 transporter in amplified linear chromosomes of various Leishmania species. This most probably indicates the essentiality of this gene in conditions of nutrient deprivation. We are presently investigating this question by comparing metabolic and biological features of the lineages containing or not the small amplified chromosome.

\section{REFERENCES}

Beverley SM 1991. Gene amplification in Leishmania. Ann Rev Microbiol 45: 417-444.

Beverley S, Coburn C 1990. Recurrent 'de novo' appearance of small linear DNAs in Leishmania major and relationship to extra-chromosomal DNAs in others species. Mol Biochem Parasitol 42: 133-142.

Chu G, Vollrath D, Davis RW 1986. Separation of large DNA molecules by contour-clamped homogeneous electric-fields. Science 234: 1582-1585.

Fu G, Melville S, Brewster S, Warner J, Barker DC 1998. Analysis of the genomic organization of a small chromosome of Leishmania braziliensis M2903 reveals two genes encoding GTP-binding proteins, one of which belongs to a new G-protein family and is an antigen. Gene 210: 325-33.

Kapler GM, Coburn CM, Beverley SM 1990. Stable transfection of human parasite Leishmania major delineates a 30kilobases region sufficient for extrachromosomal replication and expression. Mol Cell Biol 10: 1084-1094.

Lemley C, Yan S, Dole VS, Madhubala R, Cunningham ML, Beverley SM, Myler PJ, Stuart KD 1999. The Leishmania donovani LD1 locus gene ORFG encodes a biopterin transporter (BT1). Mol Biochem Parasitol 104: 93-105.

Lighthall GK, Giannini SH 1992. The chromosomes of Leishmania. Parasitol Today 8: 192-199.

Moore JB, Beverley SM 1996. Pteridine transport and recurrent amplification of extrachromosomal DNAs in Leishmania. VI Molecular Parasitology Meeting, Woods Hole, MA, p. 107.

Scholler JK, Reed S, Stuart K 1986. Molecular karyotype of species and subspecies of Leishmania. Mol Biochem Parasitol 20: 279-293.

Segovia M, Ortiz G 1997. LD1 amplifications in Leishmania. Parasitol Today 13: 342-348.

Stiles JK, Hicok PI, Shah PH, Meade, JC 1999. Genomic organization, transcription, splicing and gene regulation in Leishmania. Ann Trop Med Parasitol 93: 781-807.

Tavares C, Grimaldi Jr. G, Traub-Cseko YM 1992. Molecular karyotype analysis and mapping of housekeeping genes to chromosomes of selected species complexes of Leishmania. Mem Inst Oswaldo Cruz 87: 477-486. 